\title{
Level of Awareness and Attitude towards Topical Steroids among Medical Interns
}

\author{
Supriya Agarwal ${ }^{1}$, Suganita ${ }^{2}$, Amit Mittal ${ }^{3}$, Praveen Kumar Rathore ${ }^{4}$ \\ ${ }^{1}$ Department of Dermatology, Venereology and Leprosy, Rohilkhand Medical College and Hospital, Bareilly, \\ Uttar Pradesh, India. ${ }^{2}$ Department of Dermatology, Venereology and Leprosy, Rohilkhand Medical College \\ and Hospital, Bareilly, Uttar Pradesh, India. ${ }^{3}$ Department of Dermatology, Venereology and Leprosy, \\ Rohilkhand Medical College and Hospital, Bareilly, Uttar Pradesh, India. ${ }^{4}$ Department of Dermatology, \\ Venereology and Leprosy, Rohilkhand Medical College and Hospital, Bareilly, Uttar Pradesh, India.
}

\section{ABSTRACT}

\section{BACKGROUND}

Topical steroids are the most commonly prescribed drugs in dermatological setting, and they are also one of the most abused ones, as these drugs are very cheap, easily available over the counter, and provide quick relief in symptoms. This study aims to find the level of awareness and attitude regarding topical steroids among medical interns.

\section{METHODS}

This was a cross sectional questionnaire-based study conducted among medical interns of 2014 batch of Rohilkhand Medical College in the Department of Dermatology, Venereology and Leprosy. The study was conducted with the help of a questionnaire that was modified from the study, Verma P, et al. This was followed by a presentation on topical steroids use, misuse and what steps can be taken to prevent their rampant misuse. Finally, a feedback was taken on importance of the study.

\section{RESULTS}

Total 69 medical interns were included in the study. Fifty-two interns had previously prescribed or used topical corticosteroids. Steroids (clobetasol, betamethasone, mometasone) in combination with either tretinoin \& hydroquinone or antimicrobials were commonly abused. The commonest indication for which they were used were infections of which tinea was the most common followed by dark spots or as a fairness cream, acne, eczema, and other conditions such as pruritus, insect bite, burn, etc.

\section{CONCLUSIONS}

This study shows significant knowledge gap among medical interns regarding topical steroids. Thus, knowledge regarding topical corticosteroids is very essential and should be emphasized more during the MBBS period. More studies are required to study regarding their awareness and misuse.

\section{KEY WORDS}

Topical Steroids, Awareness, Attitude, Medical Intern
Corresponding Author:

Suganita,

D-7, Professor's Quarter, Rohilkhand Medical College and Hospital, Bareilly-243006, Uttar Pradesh, India. E-mail:suganita123@gmail.com

DOI: $10.14260 / \mathrm{jemds} / 2020 / 511$

How to Cite This Article:

Agarwal S, Suganita, Mittal A, et al. Level of awareness and attitude towards topical steroids among medical interns. J Evolution Med Dent Sci 2020;9(33):23562360, DOI: 10.14260/jemds/2020/511

Submission 29-05-2020,

Peer Review 08-07-2020,

Acceptance 14-07-2020,

Published 17-08-2020.

Copyright (C) 2020 JEMDS. This is an open access article distributed under Creative Commons Attribution License [Attribution 4.0 International (CC BY 4.0)] 


\section{BACKGROUND}

Corticosteroids are an important class of naturally occurring and synthetic steroid hormones that affect virtually every aspect of human physiology. ${ }^{1}$ Introduction of topical steroids by Sulzberger and Witten in 1952 is considered to be the most important event in the history of treatment of dermatological diseases. ${ }^{2}$ They were considered as a solution for all ills by doctors and patients and gathered rapid popularity. ${ }^{3}$ This event was soon followed by the launch of larger number of newer topical steroids molecules of different potency facilitating the treatment of various inflammatory cutaneous diseases more effective. ${ }^{4}$

Various cutaneous disorders that show response to topical steroids are pigmentary disorders (example vitiligo), vesico-bullous disorders (bullous pemphigoid, pemphigus foliaceous, cicatricial pemphigoid), papulosquamous disorders (psoriasis, lichen planus), variety of dermatitis (atopic dermatitis, prurigo, nummular eczema, cumulative insult dermatitis, pompholyx, lichen simplex chronicus, seborrheic dermatitis, allergic contact dermatitis), autoimmune diseases (lupus erythematosus, dermatomyositis, morphea), and miscellaneous conditions (like lichen sclerosis et atrophicus, alopecia areata, keloid, pyoderma gangrenosum, insect bite reaction, polymorphic eruption of pregnancy, early stage of cutaneous T-cell lymphoma). ${ }^{3}$

Topical corticosteroids are very often misused by both the medical and non-medical personnel and the reasons are easy accessibility, rapid improvement, low cost. ${ }^{5}$ Many studies have highlighted the various side effects of topical steroids. ${ }^{6-8}$ Cutaneous adverse effects, unlike systemic ones ${ }^{9}$, are more frequent and include atrophy, striae, telangiectasia, purpura, erythema, perioral dermatitis, rosacea, acne, rebound erythema, steroid addiction, topical steroid dependent face, hypo pigmentation, hypertrichosis, photosensitization, milia, tinea incognito, contact dermatitis, contact dermatitis, and tachyphylaxis. ${ }^{10}$

Among them steroid atrophy is a serious complication of long-term use of topical steroids. Depending on thickness of stratum corneum topical steroids are absorbed at different rates. ${ }^{11}$ the eyelids and genital areas absorb about $25 \%$, the palm and soles about $0.1 \%$, face about $7 \%$, upper and lower extremities about $2 \%$. And the rate of absorption is very high when ointment base is used. ${ }^{11}$

Systemic complications include suppression of hypothalamic-pituitary-adrenal axis, Cushing's disease, hypertension, peripheral oedema, ocular side effects like glaucoma and cataract, endocrinal changes such as hyperglycaemia, hypocalcaemia, decreased growth rate and femoral head osteonecrosis. ${ }^{4}$

News of cutaneous side effects of topical corticosteroids began to emerge almost after a decade of its introduction. Although, it's addictive potential was noticed much later. Klingman and Frosh first explained the condition for which they coined the term "Steroid addiction", leading to an entity "Topical Steroid Dependent/Damaged Face (TSDF)".12

Ethical use of topical steroids is very important and few prerequisites for ethical use of topical corticosteroids include: 13

- $\quad$ The right diagnosis
- The right molecule and delivery system. The characteristics of various dosage forms should be thoroughly understood so that the correct drug in right vehicle can be given in a particular situation.

- The right patient. The age, sex, and occupation of the patient play an important role in determining topical steroid use.

- The right amount, frequency, and duration. Fingertip unit devised by long and Finlay is the simplest way to explain to the patient how much topical steroid is to be applied.14 The frequency of application is dependent on patient factors such as site and occupation. The duration of treatment needs to be clearly told to the patient orally as well as in writing, and he/she should be made aware of dangers of overuse at this point.

- $\quad$ The right exit strategy. It is very important to have a clear plan in mind about tapering and stopping topical steroid use adequate control has been achieved.

- Focusing on prevention and modifiable factors. In many conditions, lasting remission or cure is only achievable if preventive actions are taken or behavioural modifications are done.

- Being aware of corticosteroid allergy.

- Effective communication. Involving and informing the patient at every step of diagnosis and treatment is the key to using topical steroid safely, ethically, and effectively.

When topical corticosteroids are advised by Medical Graduates for inappropriate indication and duration situation becomes more terrible. This is mainly due to lack of sensitization during their MBBS period. We are trying our best to make public aware about topical steroid side effects. This effort will go into vain if we ourselves are not aware that how many of our own medical graduates have proper knowledge about use of topical steroid and if we fail to aware them for the same.

Thus, through this study we aim to identify how much knowledge our medical graduates have regarding topical steroids and at same time to make them aware about its misuse.

\section{METHODS}

This was a cross-sectional questionnaire-based study conducted in the outpatient department of Dermatology, Venereology and Leprosy among the medical interns of M.B.B.S. 2014 batch of the Rohilkhand Medical College and Hospital, Bareilly regarding their level of awareness and attitude towards topical steroid. After obtaining informed verbal consent from the medical interns, study was conducted with help of a questionnaire that was modified from following study, Verma $\mathrm{P}$, et $\mathrm{al}^{5}$ as there was no prevalidated questionnaire available. The questions included in the study are as follows: whether topical steroids can be prescribed to anyone safely in any skin disease?, Do medical interns use or prescribe topical steroids to patients, self, relatives or friends?, and if yes which is the most common topical steroid prescribed or used and what are the 
indications for which they have used topical steroids?, they were also asked about whether they are aware of the various potencies of topical steroids and whether topical corticosteroids can be associated with significant cutaneous adverse effects. Lastly, they were asked whether they are aware that topical steroids are Schedule H drugs.

It was followed by a slide presentation that included various aspects about topical steroids like uses of topical steroids, their side effect and contraindications, various potencies of topical steroids available and what measures can be taken to prevent topical steroid abuse. A feedback was taken later in which interns were asked about the usefulness of the study. The sampling technique used was purposive sampling and sample size was 69 . Personal details were not asked to avoid inhibition at the end of students in answering questions and to maintain confidentiality. The data collected was collected and analyzed.

\section{RESULTS}

A total of 69 medical interns participated in this study. Thirty eight $(55.07 \%)$ interns believed TCS could be prescribed safely in any skin condition while twenty seven (39.13\%) did not believed so and four (5.79\%) were not sure.

\begin{tabular}{|c|c|c|c|c|}
\hline $\begin{array}{c}\text { Sl. } \\
\text { No. }\end{array}$ & Questions & Yes & No & $\begin{array}{c}\text { Not } \\
\text { Sure }\end{array}$ \\
\hline 1. & $\begin{array}{c}\text { Topical steroids can be prescribed to } \\
\text { anyone safely in any skin disease? }\end{array}$ & $\begin{array}{c}38 \\
(55.07 \%)\end{array}$ & $\begin{array}{c}27 \\
(39.13 \%)\end{array}$ & $\begin{array}{c}4 \\
(5.79 \%)\end{array}$ \\
\hline 2. & $\begin{array}{c}\text { Do you use/prescribe topical steroids to } \\
\text { patients, self, relatives or friends }\end{array}$ & $\begin{array}{c}52 \\
(75.36 \%)\end{array}$ & $\begin{array}{c}17 \\
(24.63 \%)\end{array}$ & - \\
\hline 3. & $\begin{array}{c}\text { If YES which is the most common topical } \\
\text { steroid prescribed/used (table - 3) }\end{array}$ & - & - & - \\
\hline 4. & $\begin{array}{c}\text { If YES what are the indications for which } \\
\text { you have used topical steroids (table - 4) }\end{array}$ & - & - & - \\
\hline 5. & $\begin{array}{c}\text { Are you aware of the various potencies of } \\
\text { topical steroids }\end{array}$ & $\begin{array}{c}27 \\
(39.13 \%)\end{array}$ & $\begin{array}{c}62 \\
(89.85 \%)\end{array}$ & - \\
\hline 6. & $\begin{array}{c}\text { Topical corticosteroids can be associated } \\
\text { with significant cutaneous adverse effects }\end{array}$ & $\begin{array}{c}22 \\
(31.88 \%)\end{array}$ & $\begin{array}{c}35 \\
(50.72 \%)\end{array}$ & $\begin{array}{c}12 \\
(17.39 \%)\end{array}$ \\
\hline 7. & Are topical steroids Schedule H drugs & $\begin{array}{c}13 \\
(18.84 \%)\end{array}$ & $\begin{array}{c}20 \\
(28.98 \%)\end{array}$ & $\begin{array}{c}36 \\
(52.17 \%)\end{array}$ \\
\hline \multicolumn{5}{|c|}{ Table 1. Level of Awareness and Attitude Towards } \\
\hline \multicolumn{5}{|c|}{ Topical Steroids among Medical Interns } \\
\hline
\end{tabular}

\begin{tabular}{|c|c|}
\hline Variant of TCS Used & Number of Interns \\
\hline $\begin{array}{c}\text { Combination (with hydroquinone \& tretinoin } \\
\text { and with antimicrobials) }\end{array}$ & $38(73.07 \%)$ \\
\hline Clobetasol & $5(9.61 \%)$ \\
\hline Betamethasone & $5(9.61 \%)$ \\
\hline Mometasone & $3(5.76 \%)$ \\
\hline Other & $1(1.92 \%)$ \\
\hline $\begin{array}{c}\text { Table 2. Commonly Prescribed / Used } \\
\text { Topical Corticosteroids by Medical Interns }\end{array}$ \\
\hline
\end{tabular}

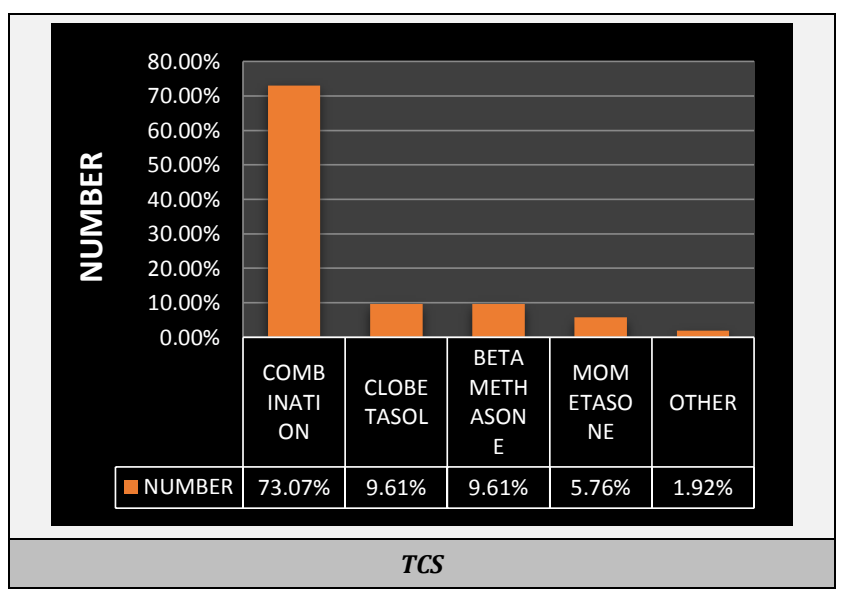

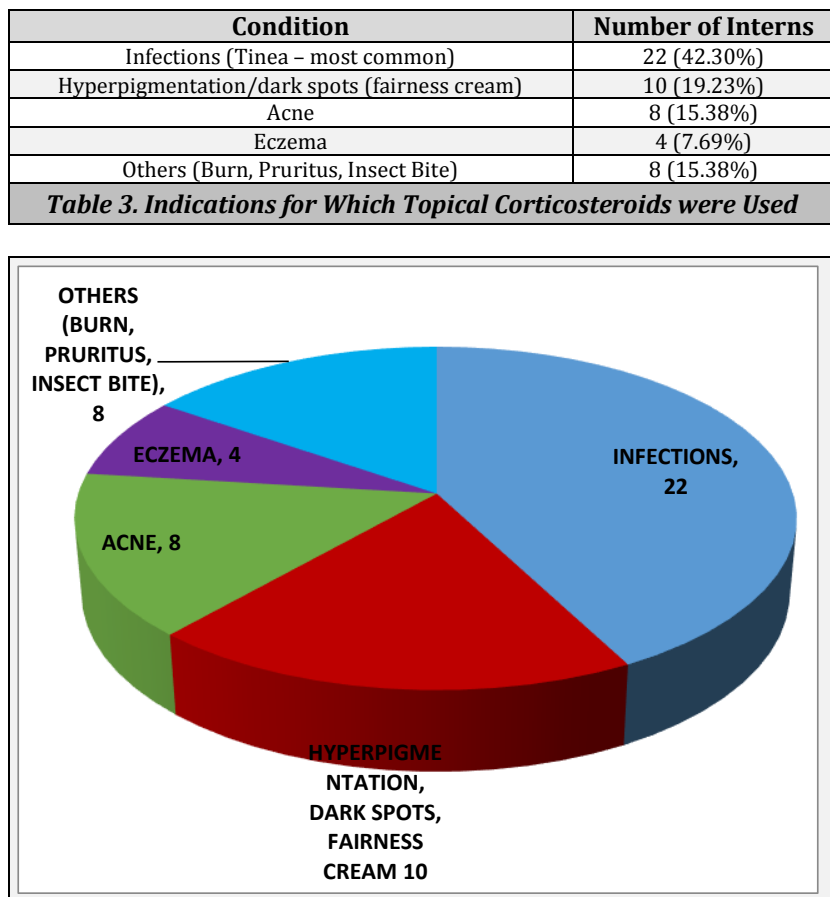

Figure 2. Indications for Which Topical Steroids were Used

Out of 69 interns fifty two (75.36\%) had previously prescribed or used topical corticosteroids in different dermatological conditions most common being topical steroids in combination (thirty eight; $73.07 \%$ ) with either hydroquinone, tretinoin, or both, antimicrobials followed by clobetasol (five; 9.61\%), betamethasone (five; 9.61\%), mometasone (three; 5.76\%), other (one; 1.92\%). (Table- 2) It has been observed during the study that interns most commonly prescribed topical steroids either to their family members, relatives or friends.

The most common indication for which they were prescribed were infections (twenty two; 40.30\%) of which tinea was the most common infection. This was followed by hyperpigmentation/dark spots or as a fairness cream (ten; 19.23\%), acne (eight; 15.38\%), eczema (four; 7.69\%), other such as pruritus, insect bite, burn, etc (eight; 15.38\%). (Table- 3)

Thirty five (50.72\%) interns were unaware about cutaneous adverse effects it produces while twelve (17.39\%) interns were not sure about it. Sixty two (89.85\%) interns were not aware of the different potencies of TCS. TCS is now schedule $\mathrm{H}$ drug was not known to twenty (20.98\%) interns while thirty six $(52.17 \%)$ were not sure. The study was found to be useful by all the interns, and was able to understand the indications, contraindications, side effects and various potencies of topical corticosteroids. They also felt the importance of prioritizing this topic during their undergraduate teaching program that usually get ignored at that time.

\section{DISCUSSION}

Topical corticosteroids are one of the most commonly prescribed medication in dermatology OPD since the introduction of "compound F" or hydrocortisone in 1952 by 
Sulzberger and Witten largely due to their ability to effectively treat several dermatoses through their antiinflammatory, anti-pruritic, melanopenic, atrophogenic, and immunosuppressive activity on the skin.,3,15 This was soon followed by the launch of a large number of newer topical steroid molecules of various potency adding more cutaneous diseases to the list of topical corticosteroid indications. ${ }^{4}$ Although, it is this very usefulness of the drug which now has become a double-edged sword. ${ }^{4}$ As topical steroids are easily available over the counter at a cheap price, their abuse and misuse has been noticed among the general population, producing many side effects. ${ }^{13}$ Some of the common side effects include atrophy, acneiform eruptions, erythema, photosensitization, rosacea like changes, hypertrichosis, hypo-hyperpigmentation, exacerbation of infection, etc. ${ }^{10}$

The present work has been conducted to study the level of awareness and attitude towards topical steroids among medical interns and at the same time giving them knowledge about various aspects of topical steroids such as their indication, contraindications, and various side effects and also making them aware about various potencies of topical steroids available in the market. Of the 69 medical interns, topical steroids were used by 52 of them, either for themselves or their relatives. The commonest indication for which they were used was infections (most commonly tinea) followed by the use for dark spots/hyperpigmentation or as fairness cream. 89.85\% interns were not aware about the various potencies of topical steroids while 47 medical interns either didn't know or were not sure that topical steroids could be associated with significant cutaneous adverse effects. This data is very disturbing and indicate a significant knowledge gap among medical interns regarding topical steroids.

In a survey conducted by Dey $\mathrm{VK}$ et $\mathrm{al}^{7}$ the main indication for which topical steroids were used was to lighten skin colour while in ours it was mainly infections of which tinea was most common. In one of the surveys conducted by Rathi SK et $\mathrm{al}^{3}$ it was found that betamethasone valerate was the most common topical steroid used while in our study topical steroids in combination with tretinoin \& hydroquinone and antimicrobials was most frequently abused. In another study done by Mishra AK et al ${ }^{16}$ clobetasol propionate was the most commonly used topical steroid.

In a study conducted by Kannan S, et al ${ }^{17} 2015$, found Betamethasone was the most common corticosteroid used by the patients followed by clobetasol. Various adverse effects observed in the study group were erythema, telangiectasia, acneiform eruption, atrophy, hypertrichosis, striae, tinea, and perioral dermatitis. In a similar study by Parul Verma et $\mathrm{al}^{5}$ where they included medical interns as well as postgraduates from various specialties, they found that post graduate students were using topical corticosteroid on patients more frequently as compared to interns and were more aware of the fact that topical steroids cannot be prescribed to everyone safely.

The main limitation of our study was small sample size, absence of representation from medical postgraduates and pharmacy students. The positive impact of our study was all of the medical interns at the end of survey became aware regarding various aspects of topical steroids.
There is an utmost need to give emphasis on topical corticosteroids during MBBS period and making it an essential component of its curriculum.

\section{CONCLUSIONS}

M.B.B.S. graduates are the backbone of Indian healthcare infrastructure and in that, medical internship is a very crucial stage as after that many of them will either start their own practice or get appointed at PHCs, CHCs or join specialty courses, and will bigin prescribing these medications. So, it is important to evaluate their level of knowledge regarding topical steroids. What we found is alarming and requires immediate steps to tackle the situation. It requires proper undergraduate training and requires regular seminars, workshops, and role plays. Additional studies should also be conducted to investigate topical steroids awareness and abuse.

Financial or Other Competing Interests: None.

\section{REFERENCES}

[1] Gupta P, Bhatia V. Corticosteroid physiology and principles of therapy. Indian J Pediatr 2008; 75(10):1039-44.

[2] Sulzberger MB, Witten VH. The effect of topically applied compound $\mathrm{F}$ in selected dermatoses. J Invest Dermatol 1952; 19(2):101-2.

[3] Rathi SK, D'Souza P. Rational and ethical use of topical corticosteroids based on safety and efficacy. Indian J Dermatol 2012; 57(4):251-9.

[4] Coondoo A, Phiske M, Verma S, et al. Side-effects of topical steroids: a long overdue revisit. Indian Dermatol Online J 2014; 5(4):416-25.

[5] Verma P, Pathania S, Suvirya S, et al. Knowledge attitude and practice survey in medical graduates regarding topical corticosteroids: a cross sectional study conducted at medical university of North India. IP Indian J Clin Exp Dermatol 2019; 5(2):133-6.

[6] Al-Dhalimi MA, Aljawahiry N. Misuse of topical corticosteroids: a clinical study in an Iraqi hospital. East Mediterr Health J 2006; 1296):847-52.

[7] Dey VK. Misuse of topical corticosteroids: a clinical study of adverse effects. Indian Dermatol Online J 2014; 5(4):436-40.

[8] Rathod PR, Shankar R, Sawant A. Clinical study of topical corticosteroids misuse. Int J Recent Trends Sci Technol 2015; 15:322-3.

[9] Valencia IC, Kerdel FA. Topical corticosteroids. In: Goldsmith LA, Katz SI, Gilcrest BA, et al, eds. Fitzpatrick's dermatology in general medicine. $8^{\text {th }}$ edn. The McGrawHill Companies Inc 2012:2695-701.

[10] Meena S, Gupta LK, Khare AK, et al. Topical corticosteroids abuse: a clinical study of cutaneous adverse effects. Indian J Dermatol 2017; 62(6):675. 
[11] Thomas J, Parimalam K. Dermatological indication and usage of topical corticosteroid. In: Lahiri K, Ed. A treatise on topical corticosteroids in dermatology. Springer 2018:23-40.

[12] Ghosh A, Sengupta A, Coondoo A, et al. Topical corticosteroid addiction and phobia. Indian J Dermatol 2014; 59(5):465-8.

[13] Saraswat A. Ethical use of topical corticosteroids. Indian J Dermatol 2014; 59(5):469-72.

[14] Long CC, Finlay AY. The finger-tip unit-a new practical measure. Clin Exp Dermatol 1991; 16(6):444-7.
[15] Manzoor S, ud din Bukhari SS, Rather SR, and et al. Topical steroid abuse: clinicoepidemiological profile. International Journal of Contemporary Medical Research 2017; 4(7):1454-6.

[16] Mishra AK, Saraswat D. Topical corticosteroid abuse in dermatology. IOSR Journal of Dental and Medical Sciences (IOSR-JDMS) 2016; 15(7):110-4.

[17] Kannan S, Khan W, Bharadwarj A, et al. Corticosteroidinduced cutaneous changes: a cross-sectional study. Indian J Pharmacol 2015; 47(6):696-8. 